\title{
Music therapy-induced changes in salivary cortisol level are predictive of cardiovascular mortality in patients under maintenance hemodialysis
}

This article was published in the following Dove Press journal:

Therapeutics and Clinical Risk Management

23 February 2017

Number of times this article has been viewed

\author{
Yi-Chou Hou' \\ Yen-Ju Lin ${ }^{2}$ \\ Kuo-Cheng Lu' \\ Han-Sun Chiang ${ }^{3}$ \\ Chia-Chi Chang ${ }^{4}$ \\ Li-King Yang'
}

'Department of Internal Medicine, Cardinal Tien Hospital, School of Medicine, Fu-Jen Catholic University, ${ }^{2}$ Department of Nursing, Taipei Medical University, ${ }^{3}$ Graduate Institute of Basic Medicine, College of Medicine, Fu Jen Catholic University, New Taipei City, ${ }^{4}$ School of Gerontology Health Management, College of Nursing, Taipei Medical University, Taipei, Taiwan, Republic of China
Correspondence: Chia-Chi Chang School of Gerontology Health Management, College of Nursing, Taipei Medical University, $250 \mathrm{Wu}$-Xing Street, Taipei I I0, Taiwan, Republic of China Tel/fax +886 22736 I66 I 6336

Email cchang@tmu.edu.tw

\section{Li-King Yang}

Department of Internal Medicine, Cardinal Tien Hospital, School of Medicine, Fu-Jen Catholic University, 362 Chung-Cheng Road, Hsin-Tien District, New Taipei City 23I48, Taiwan, Republic of China

Tel +8862 2219 3391 65343

Fax +886 22185579

Email margaretlaiking@yahoo.com
Background: Music therapy has been applied in hemodialysis (HD) patients for relieving mental stress. Whether the stress-relieving effect by music therapy is predictive of clinical outcome in HD patients is still unclear.

Methods: We recruited a convenience sample of 99 patients on maintenance HD and randomly assigned them to the experimental $(n=49)$ or control $(n=50)$ group. The experimental group received relaxing music therapy for 1 week, whereas the control group received no music therapy. In the experimental group, we compared cardiovascular mortality in the patients with and without cortisol changes.

Results: The salivary cortisol level was lowered after 1 week of music therapy in the experimental group $(-2.41 \pm 3.08 \mathrm{vs} 1.66 \pm 2.11 \mathrm{pg} / \mathrm{mL}, P<0.05)$, as well as the frequency of the adverse reaction score $(-3.35 \pm 5.76$ vs $-0.81 \pm 4.59, P<0.05)$, the severity of adverse reactions score $(-1.93 \pm 2.73$ vs $0.33 \pm 2.71, P<0.05)$, and hemodialysis stressor scale (HSS) score $(-6.00 \pm 4.68$ vs $-0.877 \pm 7.08, P<0.05)$. The difference in salivary cortisol correlated positively with HD stress score scales $(r=0.231, P<0.05)$, systolic blood pressure $(r=0.264, P<0.05)$, and respiratory rates $(r=0.369, P<0.05)$ and negatively with finger temperature $(r=-0.235, P<0.05)$ in the total study population. The 5-year cardiovascular survival in the experimental group was higher in patients whose salivary cortisol lowered by $<0.6 \mathrm{pg} / \mathrm{mL}$ than that in patients whose salivary cortisol lowered by $>0.6 \mathrm{pg} / \mathrm{mL}(83.8 \%$ vs $63.6 \%, P<0.05)$.

Conclusion: Providing music during HD is an effective complementary therapy to relieve the frequency and severity of adverse reactions, as well as to lower salivary cortisol levels. Differences in salivary cortisol after music therapy may predict cardiovascular mortality in patients under maintenance HD.

Keywords: music therapy, maintenance hemodialysis, salivary cortisol

\section{Abbreviations}

$\mathrm{CV}$, cardiovascular; ESRD, end-stage renal disease; HD, hemodialysis; HPA, hypothalamus-pituitary-adrenal; HSS, Hemodialysis Stressor Scale.

\section{Introduction}

Taiwan currently has the highest incidence and prevalence of chronic kidney disease requiring long-term HD worldwide. ${ }^{1}$ HD increases the survival of such patients, but it concurrently increases stress levels. In addition, HD can result in adverse reactions, such as hypotension, muscle cramping, nausea, vomiting, headache, and chest pain. ${ }^{2}$ Elderly patients with ESRD often have comorbidities such as cardiovascular disease and autonomic dysfunction, which limit their ability to cope with physiological stressors and 
maintain hemodynamic stability during the HD procedure. Therefore, patients receiving HD are under greater physical and mental stress than the general population. ${ }^{3}$ Beyond the stress, cardiovascular event is still the leading cause of death in HD patients. Vascular calcification, hyperphosphatemia, left ventricular hypertrophy, sympathetic activation, chronic inflammation, and other comorbidities predict $\mathrm{CV}$ events in HD patients. ${ }^{4,5}$ Recently, the linkage between stress and cardiovascular disease has been proposed, but the correlation in ESRD patients is still lacking. ${ }^{6,7}$

Adaptation to stress involves the HPA axis. The resulting gene transcription results in a cascade of sequential proteinprotein interactions that activate the immune system and hormone metabolism. The level of unbound free cortisol has been shown to be an indicator of HPA axis activation during stress. ${ }^{8}$ Measurement of serum cortisol has been applied to several psychiatric conditions such as depression; however, such measurement is costly and many factors can falsely raise the serum level, including the venipuncture procedure itself. ${ }^{9}$ The salivary cortisol level correlates favorably with the serum cortisol level, and the salivary cortisol concentration reflects the biologically active serum-unbound cortisol level and is thus unaffected by elevations in cortisol-binding globulin, which confuse the interpretation of serum cortisol levels. Moreover, saliva is easy to collect and the collection procedure is noninvasive and stress free. ${ }^{10}$ Therefore, many studies have used salivary cortisol as a biomarker reflecting physical stress and emotional stress, ${ }^{11-13}$ and the variation of salivary cortisol predicts cardiovascular mortality in several studies. ${ }^{14,15}$

Relaxing music is defined as having a slow tempo $(60 \times 80$ crotchet beats/min), low-to-medium pitch, low volume, and melodious rhythms involving mostly wind instruments. ${ }^{16}$ The activation of parasympathetic tone induces changes in blood pressure (BP), heart rate, respiratory rate, temperature, and serum-free fatty acids that have beneficial effects on the body's metabolism. ${ }^{17-20}$ Music therapy has been used in clinical practice for mood stabilization before invasive procedures or in intensive care units. ${ }^{21,22}$ The stress-lowering effect of music has been associated with lowering cortisol levels. ${ }^{23}$ In other words, relaxing music therapy relieves mental stress, and cortisol release is alleviated as the stress is relieved.

Lin et $\mathrm{a}^{24}$ demonstrated that music therapy not only reduces the frequency and severity of adverse reactions and stress scores during dialysis but also increases finger oxygen saturation and decreases the respiratory rate after 1 week of HD treatment. However, the effect of music therapy on cortisol secretion has not been demonstrated in patients on maintenance HD, and whether the differences induced by music therapy can be utilized as a predictor of clinical outcome is still unknown. We hypothesized that relaxing music therapy relieves mental stress in patients on maintenance HD and salivary cortisol level. In addition, we intended to assess whether the differences can predict clinical outcome, such as cardiovascular mortality.

\section{Methods}

\section{Design and setting}

This 2-week study was performed in the Hemodialysis Center of Cardinal Tien Hospital, New Taipei City, Taiwan. The study was a prospective randomized clinical trial. The Ethics Committee on Human Studies at Cardinal Tien Hospital approved the study protocol (trial of register number: CTH-99-1-2A02). We initiated the study on April 1, 2009, and completed on April 30, 2010. We obtained written informed consent from each patient who participated. During the study, 112 patients deemed eligible for enrollment were aged $\geq 60$ years and known to have ESRD for at least 3 months, receive maintenance HD three times a week ( $4 \mathrm{~h}$ per session), and able communicate effectively in Mandarin or Taiwanese. Thirteen patients with severe cognitive or hearing impairments and those with pacemakers were excluded. Finally, we recruited a convenience sample of 99 HD patients and randomly assigned them to the experimental $(n=49)$ or control ( $n=50)$ group. We measured the impact of music therapy on stressors and adverse reactions by administering the HD Adverse Reactions Self-Assessment Scale and HSS in the final sessions of HD in the first and second weeks. Both scales were questionnaires. We reviewed the physiological indices every $30 \mathrm{~min}$ for the entire HD treatment and averaged data from eight time points $(30,60,90,120,150,180,210$, and $240 \mathrm{~min}$ after HD initiation) to obtain the postintervention measures for each patient. In the experimental and control groups, predialysis salivary cortisol was collected on the final HD in the first and second weeks, respectively.

\section{Intervention}

All the participants received HD at 7-8 am. During the whole session of HD, all the participants were asked to lie in their own beds in the dialysis center. The participants in the control group were asked to adhere to previous habits during HD such as watching TV and reading for 1 week. In the experimental group, the participants were asked to select and create their own music playlists according to their preference in the first week. During the second week, the experimental group listened to relaxing music. In the first week, we encouraged the participants in the experimental group to choose their favorite music styles by listening to the 
first $30 \mathrm{~s}$ of each of the songs on the complete playlist with 5 s intervals between songs. There were three songs to choose from in each music category, and the participants were free to select and delete songs and music categories to create their own playlists, which we then recorded for each participant. All available selections were melodic instrumental music with a tempo of $60-80$ beats/min. During the second week, the participants in the experimental group received music as therapy during every HD session. They wore earphones to eliminate background noise and selected music from their own playlists. The participants could listen to music for the first $20 \mathrm{~min}$ of every hour for the first $3 \mathrm{~h}$ of HD. For the fourth hour, we asked the participants to listen to music during the final $20 \mathrm{~min}$ of HD treatment. We did not provide the control group with any music during HD.

\section{Instruments}

\section{Demographic data}

To account for possible confounding factors during analysis, we recorded and controlled for the following demographic, laboratory, and clinical data: age, gender, duration of HD, biochemical parameters, and comorbidity.

\section{Physiological indicators}

We used a biological monitoring system (GE Medical Systems Information Technologies, Inc., Milwaukee, WI, USA) to monitor and record BP, heart rate, respiratory rate, and oxygen saturation. This monitor system is approved by the Department of Health, Executive Yuan, and the Bureau of Standards Metrology and Inspection, Taiwan. We measured finger surface temperature using the TEMPview Temperature Feedback Monitor, which has an accuracy of within $0.1^{\circ} \mathrm{C}$ (TM-903A; Ronmac Int. Corp., Taipei, Taiwan; manufactured in 2009).

\section{HD Adverse Reactions Self-Assessment Scale}

Adapted from relevant literature and clinical nursing management experience, we applied the self-assessment scale contains 17 common adverse reactions that may occur during HD in Chinese version. ${ }^{2,25}$ We used a 4-point Likert-type scale to quantify symptom frequency $(0=$ none, $1=$ once or twice, $2=$ three to five times, and $3=$ more than five times) and severity ( $1=$ mildly ill, $2=$ moderately ill, $3=$ seriously ill, and 4= extremely ill). Frequency scores ranged between 0 and 51, with higher scores indicating a higher frequency. Severity scores ranged between 17 and 68, with higher scores likewise representing a greater severity. The Cronbach's alpha of the scale was 0.662 , and the coefficient of variation was 0.91 .

\section{Hemodialysis Stressor Scale}

The $\mathrm{HSS}^{26}$ is a 32 -item scale used for rating the incidence and severity of stressors associated with HD. The subjects rated the extent of being troubled by each of the 32 stressors by using a 4 -point scale $(0=$ not at all, $1=$ slightly, $2=$ moderately, and $3=$ a great deal). We obtained a subtotal score for each construct by summing the ratings for each of them; the higher the score was, the greater the stress. We used the HSS for both long-term recall (ie, 1-2 months prior to the study) and more immediate recall (during the second week of the study period). The Cronbach's alpha of this scale was 0.905 in this study.

\section{Salivary cortisol measurement}

To ensure reliable measurement of cortisol levels, the experimental and control groups were instructed to avoid excessive levels of physical activity $24 \mathrm{~h}$ before $\mathrm{HD}$, to fast the night before testing, and not to drink or brush their teeth $30 \mathrm{~min}$ before testing. During HD, the patients were restricted to bed rest and were not permitted to exercise. Later, we placed cotton swabs in the sublingual area for $2 \mathrm{~min}$ to collect at least $3 \mathrm{~mL}$ of saliva. The sample cotton swab was sent to the laboratory, and the saliva was centrifuged $(1,500 \times g, 15 \mathrm{~min})$ at $18^{\circ} \mathrm{C}$. Saliva samples were collected using the passive drool method at the end of HD, immediately placed on ice, and then stored at $-80^{\circ} \mathrm{C}$ until further analysis. The cortisol levels were quantified using a Cortisol ELISA kit. The range of detection using this method has been reported to be $0.54-33.72 \mathrm{pg} /$ $\mathrm{mL}$, and the intra- and interassay coefficients of variation have been reported to be $28.4 \%-20.1 \%$ and $23.8 \%-18.6 \%$, respectively (Cayman Chemical Number 500360).

\section{Subgroup in the experimental group: salivary cortisol lowered $>0.6 \mathrm{pg} / \mathrm{mL}$}

After completing the salivary cortisol measurement, we observed patients from April 1, 2009, to December 31, 2014, for overall survival and cardiovascular survival between the experimental and control groups. In the experimental group, we divided patients into the following two subgroups: 1) patients whose salivary cortisol levels decreased $>0.6 \mathrm{pg} / \mathrm{mL}$ after 1 week of music therapy and 2) patients whose salivary cortisol levels decreased $<0.6 \mathrm{pg} / \mathrm{mL}$ or increased after 1 week of music therapy. The cutoff value $0.6 \mathrm{pg} / \mathrm{mL}$ was defined by first quartile of the data set in the experimental group (the order 38 of 49, as listed in Table S1).

\section{Survival}

Death records were made prospectively by considering all patients who had been enrolled at least 3 months between 
April 1, 2009, and December 31, 2014. Each medical chart was reviewed, and a physician assigned the cause of death on the basis of all of the available clinical information at the emergency department or intensive care units at the Cardinal-Tien Hospital. Patients who were lost to follow-up after study completion were excluded. Cardiovascular mortality was defined as any death directly related to cardiovascular system dysfunction in Cardinal-Tien Hospital (stroke, myocardial infarction, congestive heart failure, or sudden death).

\section{Statistical analysis}

Continuous variables are expressed as mean \pm standard deviation, and categorical values are expressed as percentages. In addition, the median value is used for the frequency of adverse reaction, severity of adverse reactions scales, and HSS scores. We tested the normal distribution of samples by using the Kolmogorov-Smirnov test and performed comparisons between groups by using the Student's $t$-test or Mann-Whitney $U$-test (according to data characteristics). We used Fisher's exact test or chi-square analysis to test categorical data and Wilcoxon's signed-rank test to analyze differences between pre- and posttest values in the experimental and control groups. Spearman's rank correlation coefficient test was used to evaluate the correlation between the difference in cortisol and differences in other parameters such as BP, respiratory rates, peripheral oxygen saturation, and HSS scores in the entire study population. All statistical analyses were performed using the statistical package SPSS for Windows (Version X; SPSS, Inc., Chicago, IL, USA).

\section{Results}

\section{Baseline data and physiological parameters}

The demographic, laboratory, and clinical details are listed in Tables 1 and 2. The patients in the experimental group experienced a longer duration of maintenance HD (5.72 \pm 4.70 vs $3.74 \pm 2.71$ years, $P<0.05$ ). The HD duration has no correlation with parameters such as predialysis frequency of adverse reaction score $(r=0.136, P>0.05)$, severity of adverse reaction scores $(r=0.018, P>0.05)$ or HSS score $(r=0.065$, $P>0.05$ ), or other physiological indicators before music therapy. The percentage of female gender was lower in the experimental group $(51.0 \%)$ than in the control group $(76 \%$, $P=0.024)$, but the percentage of gender was not related to the percentage of comorbidities such as diabetes mellitus $(P=0.201)$, hypertension $(P=0.263)$, coronary artery disease
Table I Demographic data of control and experimental groups

\begin{tabular}{|c|c|c|c|}
\hline Characteristics & $\begin{array}{l}\text { Control } \\
(n=50)\end{array}$ & $\begin{array}{l}\text { Experiment } \\
(n=49)\end{array}$ & $P$-value \\
\hline HD duration (years) & $3.74 \pm 2.71$ & $5.72 \pm 4.70$ & $0.031 *$ \\
\hline Age (years) & $75.47 \pm 8.48$ & $70.5 I \pm 8.00$ & 0.421 \\
\hline Sex (female) & $38(76.0 \%)$ & $25(51.0 \%)$ & $0.024 *$ \\
\hline \multicolumn{4}{|l|}{ Etiology entering hemodialysis } \\
\hline Hypertension & 37 (75.5\%) & $33(67.3 \%)$ & 0.98 \\
\hline Diabetes mellitus & $26(52.0 \%)$ & $25(51.0 \%)$ & 0.67 \\
\hline Polycystic kidney disease & $2(4.0 \%)$ & I (2.0\%) & 0.842 \\
\hline Coronary artery disease & $12(24.0 \%)$ & $13(26.5 \%)$ & 0.974 \\
\hline Genitourinary tract malignancy & $4(8.0 \%)$ & $2(4.0 \%)$ & 0.698 \\
\hline
\end{tabular}

Notes: Data are expressed as the mean \pm standard deviation, or $\mathrm{n}(\%)$. $* \mathrm{P}<0.05$. Abbreviation: HD, hemodialysis.

$(P=0.780)$, polycystic kidney disease $(P=0.782)$, and genitourinary tract malignancy $(P=0.658)$.

The mean diastolic pressure in the control group was marginally lower than that in the experimental group $(P=0.049)$. Other predialysis biochemistry and hematologic data did not differ significantly between two groups. There were also no significant differences in the percentage of patients with comorbidities or primary etiology for HD between the experimental and control groups. Although the cortisol level before the intervention was similar between the control and experimental groups, the cortisol level was significantly lowered in the experimental group after music therapy (control group: $7.90 \pm 5.33 \mathrm{pg} / \mathrm{mL}$; experimental group: $4.99 \pm 2.89 \mathrm{pg} / \mathrm{mL}, P<0.05)$.

\section{Analysis of variables before and after music therapy}

In the experimental group, the frequency and severity of adverse reactions as well as scores on the HSS decreased significantly after three sessions (1 week) of music as therapy (Table 3). The median values of frequency of adverse reaction, severity of adverse reaction score, and HSS score were 1, 1, and 24, respectively, in the experimental group. The median values of frequency of adverse reaction, severity of adverse reaction score, and HSS score were 1,1 , and 27 , respectively, in the control group. Psychiatric parameters, such as the frequency of adverse reaction score $(-3.35 \pm 5.76$ vs $-0.81 \pm 4.59, P<0.05)$, the severity of adverse reactions score $(-1.93 \pm 2.73$ vs $0.3 \pm 2.71, P<0.05)$, and HSS score $(-6.00 \pm 4.68$ vs $-0.877 \pm 7.08, P<0.05)$, were lower in the experimental group. The respiratory rate significantly decreased $(-2.88 \pm 2.49$ vs $-0.09 \pm 1.66$ breaths/ min, $P<0.05)$, and oxygen saturation significantly increased $(1.32 \pm 2.66$ vs $-0.09 \% \pm 0.84 \%, P<0.05)$. We found no significant differences in the heart rate or systolic or diastolic 
Table 2 Physical parameters, stress scales, and laboratory data between control and experimental groups before the intervention

\begin{tabular}{|c|c|c|c|c|}
\hline Parameters & Control $(n=50)$ & Experiment $(n=49)$ & Reference value & $P$-value \\
\hline \multicolumn{5}{|l|}{ Stress scales } \\
\hline Frequency of adverse reaction score & $3.07 \pm 4.54$ & $4.04 \pm 7.13$ & & 0.482 \\
\hline Severity of adverse reactions score & $1.93 \pm 2.28$ & $2.63 \pm 3.93$ & & 0.246 \\
\hline Hemodialysis Stressor Scale score & $28.58 \pm 14.74$ & $27.28 \pm 16.58$ & & 0.659 \\
\hline \multicolumn{5}{|l|}{ Physical parameters } \\
\hline $\mathrm{SBP}(\mathrm{mmHg})$ & $134.74 \pm 18.19$ & $137.32 \pm 19.08$ & & 0.461 \\
\hline $\mathrm{DBP}(\mathrm{mmHg})$ & $68.11 \pm 6.29$ & $71.04 \pm 9.19$ & & $0.049 *$ \\
\hline Heart rate (beats/min) & $70.67 \pm 10.73$ & $71.39 \pm 14.46$ & & 0.761 \\
\hline Respiratory rate (breaths/min) & $\mid 8.73 \pm 1.91$ & $19.01 \pm 2.78$ & & 0.531 \\
\hline Finger temperature $\left({ }^{\circ} \mathrm{C}\right)$ & $31.40 \pm 1.96$ & $31.97 \pm 1.88$ & & 0.119 \\
\hline Oxygen saturation (\%) & $98.16 \pm 0.95$ & $97.89 \pm 2.68$ & & 0.466 \\
\hline \multicolumn{5}{|l|}{ Laboratory data } \\
\hline Pre-therapy salivary cortisol (pg/mL) & $6.24 \pm 4.67$ & $7.40 \pm 4.23$ & & 0.982 \\
\hline Post-therapy salivary cortisol ( $\mathrm{pg} / \mathrm{mL})$ & $7.90 \pm 5.33$ & $4.99 \pm 2.89$ & & $0.012^{*}$ \\
\hline Hematocrit (\%) & $30.16 \pm 3.90$ & $31.88 \pm 4.95$ & $33-36$ & 0.052 \\
\hline$K t / V$ & $1.46 \pm 0.37$ & $1.46 \pm 0.34$ & $1.2-1.7$ & 0.974 \\
\hline Calcium (mg/dL) & $9.02 \pm 0.72$ & $9.19 \pm 0.63$ & $8.5-10.1$ & 0.892 \\
\hline Phosphorous (mg/dL) & $5.04 \pm 1.53$ & $4.49 \pm 1.12$ & $3.5-5.5$ & 0.069 \\
\hline Albumin $(g / d L)$ & $3.87 \pm 0.69$ & $3.82 \pm 0.35$ & $3.4-5$ & 0.236 \\
\hline Potassium $(\mathrm{mEq} / \mathrm{L})$ & $4.35 \pm 0.83$ & $4.49 \pm 0.81$ & $3.5-5.0$ & 0.845 \\
\hline Intact parathyroid hormone (pg/mL) & $422.36 \pm 407.42$ & $378.58 \pm 395.24$ & $150-300$ & 0.837 \\
\hline
\end{tabular}

Notes: Data are expressed as the mean \pm standard deviation. $* P<0.05$.

Abbreviations: DBP, diastolic blood pressure; SBP, systolic blood pressure.

blood pressure (BP). However, salivary cortisol secretion decreased significantly after music therapy in the experimental group $(-2.41 \pm 3.08$ vs $1.66 \pm 2.11 \mathrm{pg} / \mathrm{mL}, P<0.05)$.

\section{Correlation between the difference in salivary cortisol and the differences in other parameters: HSS score and physiological indicators}

Table 4 demonstrates the correlation between the difference in salivary cortisol level and the differences in other parameters in the entire study population. The difference in salivary cortisol positively correlated with the difference in HSS scores $(r=0.231, P<0.05)$, systolic BP $(r=0.264, P<0.05)$, and the respiratory rates $(r=0.369$, $P<0.05)$. The difference in the salivary cortisol negatively correlated with the finger temperature $(r=-0.235$, $P<0.05)$. No significant correlation was found between the difference in the salivary cortisol level and the differences in other physiological indicators, such as oxygen saturation.

Table 3 Comparison of changes in variables before and after music therapy between the two groups

\begin{tabular}{|c|c|c|c|}
\hline Variable & Experimental group $(n=49)$ & Control group $(n=50)$ & $P$-value \\
\hline Frequency of adverse reactions score & $-3.35 \pm 5.76$ & $-0.8 I \pm 4.59$ & $0.01 *$ \\
\hline Severity of adverse reactions score & $-1.93 \pm 2.73$ & $0.33 \pm 2.71$ & $<0.00 I^{* * *}$ \\
\hline Hemodialysis Stressor Scale score & $-6.00 \pm 4.68$ & $-0.877 \pm 7.08$ & $<0.00 \mathrm{I}^{* *}$ \\
\hline $\mathrm{SBP}(\mathrm{mmHg})$ & $-3.13 \pm 14.17$ & $0.27 \pm \mid 4.01$ & 0.201 \\
\hline $\mathrm{DBP}(\mathrm{mmHg})$ & $-1.63 \pm 6.68$ & $-0.60 \pm 8.04$ & 0.458 \\
\hline Heat rate (beats/min) & $0.68 \pm 7.39$ & $1.15 \pm 5.23$ & 0.697 \\
\hline Respiratory rate (breaths/min) & $-2.88 \pm 2.49$ & $-0.09 \pm 1.66$ & $<0.001 * *$ \\
\hline Finger temperature $\left({ }^{\circ} \mathrm{C}\right)$ & $0.57 \pm 1.49$ & $0.25 \pm 1.43$ & 0.253 \\
\hline Oxygen saturation (\%) & $1.32 \pm 2.66$ & $-0.09 \pm 0.84$ & $<0.00 I^{* *}$ \\
\hline Salivary cortisol level & $-2.4 I \pm 3.08$ & $1.66 \pm 2.11$ & $<0.00 I^{* *}$ \\
\hline
\end{tabular}

Notes: Data are described as mean + standard deviation. The Mann-Whitney U-test was used for this analysis. $* P<0.05$. $* * P<0.001$.

Abbreviations: DBP, diastolic blood pressure; SBP, systolic blood pressure. 
Table 4 Correlation between the change in salivary cortisol and other parameters

\begin{tabular}{lll}
\hline Parameter & Spearman's correlation & $P$-value \\
\hline Hemodialysis Stressor Scale & 0.231 & $0.021^{*}$ \\
Systolic blood pressure & 0.264 & $0.008^{* *}$ \\
Heart rate & -0.073 & 0.47 \\
Respiratory rate & 0.369 & $0.000^{* *}$ \\
Body temperature & -0.235 & $0.019^{*}$ \\
Oxygen saturation & -0.102 & 0.317 \\
\hline
\end{tabular}

Notes: $* P<0.05$. $* * P<0.01$.

\section{Comparison of change in variables after music therapy in the experimental group whose salivary cortisol level decreased $>0.6 \mathrm{pg} / \mathrm{mL}$ or increased}

In the experimental group, salivary cortisol level increased after music therapy in 5 patients and decreased in 44 patients. We determined whether the salivary cortisol level decreased by $>0.6 \mathrm{pg} / \mathrm{mL}$. We compared the predialysis biochemistry parameters in these two subgroups and found that mean predialysis blood glucose level was significantly lower in patients whose salivary cortisol decreased $>0.6 \mathrm{pg} / \mathrm{mL}$ (121.00 \pm 41.02 vs $187.70 \pm 130.18 \mathrm{mg} / \mathrm{dL}, P<0.05)$. There was no difference in the other laboratory parameters (Table 5).

\section{Kaplan-Meier estimates for cardiovascular survival and overall survival in the experimental group whose salivary cortisol level decreased $>0.6 \mathrm{pg} / \mathrm{mL}$ or increased}

We compared the Kaplan-Meier estimates for 5-year overall survival and cardiovascular survival between the experimental group with or without salivary cortisol that decreased $>0.6 \mathrm{pg} / \mathrm{mL}$. There was no difference in the overall survival in the subgroup analysis (Figure 1). However, 5 -year cardiovascular survival was higher (81.6\% vs $63.6 \%$, $P<0.05)$ in the patients whose salivary cortisol level decreased $>0.6 \mathrm{pg} / \mathrm{mL}$ (Figure 2).

\section{Discussion}

Our results show that 1 week of relaxing music therapy yielded improvement by relieving the physical stress and mental stress in patients on maintenance HD and led to a decrease in salivary cortisol levels. The difference in salivary cortisol correlates with HSS score and respiratory rates positively and oxygen saturation negatively.

In this study, we investigated whether music therapy can reduce stress in patients on maintenance HD. The mean salivary cortisol level in our patients was $6.83 \pm 4.45 \mathrm{pg} / \mathrm{mL}$ at $11 \mathrm{am}$, which is higher than that in the general population. Raff and Trivedi ${ }^{27}$ demonstrated that the nadir of plasma cortisol and salivary cortisol in patients with ESRD was higher than that in patients with normal renal function. Evaluating cortisol levels is more difficult in patients with chronic renal failure than in patients with normal renal function because the former tend to have decreased renal excretion of cortisone and renal metabolite of cortisol ${ }^{28}$ and decreased cortisol binding to albumin. Furthermore, patients on HD tend to experience several adverse effects, including hypotension, chest pain, and fatigue. Such physical stress activates the HPA axis, resulting in the secretion of cortisol. Several studies have shown that adrenocorticotropic hormone response is blunted in ESRD patients, rendering them less sensitive to the glucocorticoid-negative feedback system. ${ }^{29-31}$ Other studies have shown that a longer HD duration can disturb the HPA, resulting in chronic inflammation with elevated $\mathrm{C}$-reactive protein and interleukin-6 levels, which also influence the negative feedback of glucocorticoids. ${ }^{27,32-34}$ Therefore, higher salivary cortisol levels are reasonable in patients on maintenance HD compared to those in the general population.

In the experimental group, 1 week of music therapy not only lowered the frequency of adverse reactions, the severity of adverse reactions, and HSS scores but also resulted in a decrease in the respiratory rate with an increase in peripheral oxygen saturation. The change of salivary cortisol in the total study population positively correlated with systolic BP and respiratory rate. Several studies have discussed the effects of music on cortisol secretion and stress relief. Nilsson ${ }^{34}$ demonstrated that music therapy relieved stress after coronary artery bypass surgery by lowering endocrine levels. In addition, Trappe ${ }^{22}$ noticed that the level of anxiety and the level of cortisol were significantly lower in patients who received music therapy. The mechanism governing the effect on lowering cortisol levels is not well understood. Thoma et $\mathrm{al}^{23}$ evaluated the effects of music therapy on sympathetic tone and the HPA axis and found that music therapy did not immediately lower the cortisol and catecholamine release, but it could induce rapid recovery after exposure to stressors. Based on this evidence, music therapy may affect stress relief by downregulating cortisol release. To date, music therapy has been proposed as adjunctive management for relieving anxiety. In our study, music therapy lowers basal cortisol secretion in ESRD patients who are hypercortisolemic.

We found that patients with cortisol lowering by $0.6 \mathrm{pg} / \mathrm{mL}$ in the experimental group had less cardiovascular mortality within 5-year follow-up duration (Figure 1, $P=0.034$ ). 
Table 5 Demographic data between patients with cortisol lowered $>0.6 \mathrm{pg} / \mathrm{mL}$ and patients with cortisol lowered $<0.6 \mathrm{pg} / \mathrm{mL}$ or increased

\begin{tabular}{|c|c|c|c|c|}
\hline Laboratory & $\begin{array}{l}\text { Cortisol level without } \\
\text { lowering }>0.6 \mathrm{pg} / \mathrm{mL} \\
(\mathrm{n}=13)\end{array}$ & $\begin{array}{l}\text { Cortisol level } \\
\text { lowering }>0.6 \mathrm{pg} / \mathrm{mL} \\
(\mathrm{n}=36)\end{array}$ & $\begin{array}{l}\text { Reference } \\
\text { value }\end{array}$ & $P$-value \\
\hline Hematocrit (\%) & $31.68 \pm 5.39$ & $31.93 \pm 3.25$ & $33-36$ & 0.156 \\
\hline Predialysis blood urea nitrogen (mg/dL) & $67.38 \pm 17.74$ & $69.00 \pm 16.59$ & $7-18$ & 0.904 \\
\hline Predialysis creatinine $(\mathrm{mg} / \mathrm{dL})$ & $9.8 I \pm 2.68$ & $8.85 \pm 2.33$ & $0-1.0$ & 0.549 \\
\hline $\mathrm{Kt} / \mathrm{V}$ & $1.50 \pm 0.30$ & $1.28 \pm 0.55$ & & 0.225 \\
\hline Calcium (mg/dL) & $9.26 \pm 0.64$ & $9.02 \pm 0.73$ & $8.5-10.1$ & 0.84 \\
\hline Phosphorous (mg/dL) & $5.08 \pm 1.17$ & $4.65 \pm 0.99$ & $3.5-5.5$ & 0.777 \\
\hline Predialysis sugar (mg/dL) & $121.00 \pm 41.02$ & $187.70 \pm 130.18$ & & 0.001 \\
\hline Albumin $(g / d L)$ & $3.84 \pm 0.34$ & $3.69 \pm 0.28$ & $3.4-5$ & 0.413 \\
\hline Uric acid (mg/dL) & $7.09 \pm 1.09$ & $7.08 \pm 1.13$ & $3.5-7.2$ & 0.671 \\
\hline Alkaline phosphate (U/L) & $77.58 \pm 35.06$ & $86.54 \pm 41.84$ & $50-136$ & 0.564 \\
\hline GOT (U/L) & $18.47 \pm 5.95$ & $22.63 \pm 8.08$ & $<40$ & 0.147 \\
\hline GPT (U/L) & $16.63 \pm 7.78$ & $21.00 \pm 12.95$ & $<40$ & 0.14 \\
\hline Potassium (mEq/L) & $4.57 \pm 0.83$ & $4.12 \pm 0.60$ & $3.5-5.0$ & 0.182 \\
\hline Ferritin $(\mathrm{ng} / \mathrm{mL})$ & $503.06 \pm 368.87$ & $487.13 \pm 392.54$ & $200-800$ & 0.869 \\
\hline TSAT (\%) & $0.33 \pm 0.11$ & $0.29 \pm 0.12$ & $10-50$ & 0.683 \\
\hline Total bilirubin (mg/dL) & $0.69 \pm 0.24$ & $0.62 \pm 0.11$ & & 0.431 \\
\hline Intact parathyroid hormone & $345.30 \pm 380.33$ & $427.89 \pm 425.01$ & $150-300$ & 0.925 \\
\hline
\end{tabular}

Note: Data are expressed as the mean \pm SD.

Abbreviations: SD, standard deviation; GOT, glutamic-oxalocetic transaminase; GPT, glutamic-pyruvic transaminase; TSAT, transferrin saturation.

Patients receiving HD suffer mental stress because of physical illness and discomfort during treatment. Mental stress with anxiety disorder or depression is predictive of cardiovascular mortality. ${ }^{35,36}$ Mental stress, such as depression or anxiety, is not only common but also predictive of clinical outcomes in patients receiving renal replacement therapy. Griva et $\mathrm{al}^{37}$

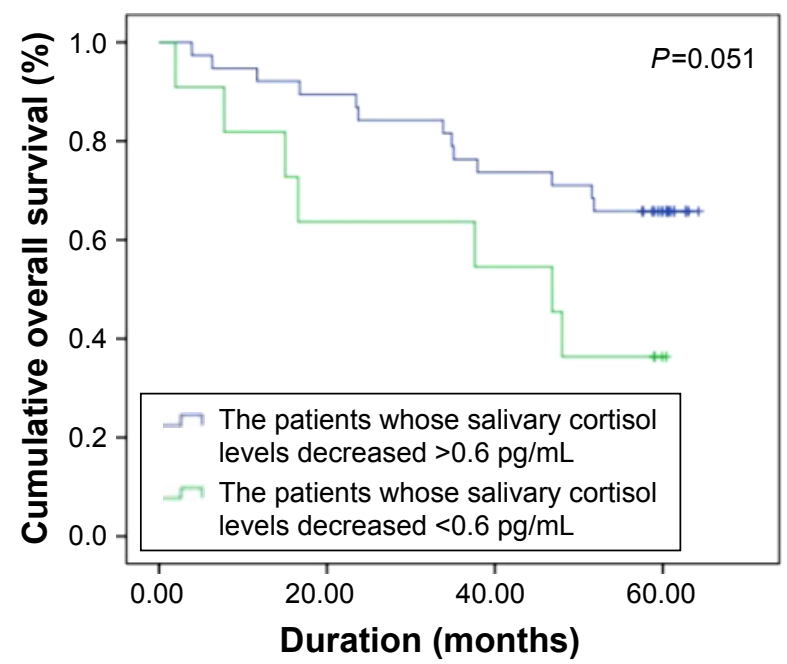

\begin{tabular}{|l|c|c|c|c|c|c|c|c|}
\hline Number at risk & 0 & 10 & 20 & 30 & 40 & 50 & 60 & (months) \\
\hline $\begin{array}{l}\text { With cortisol } \\
\text { variability }\end{array}$ & 37 & 35 & 33 & 31 & 27 & 26 & 24 & \\
\hline $\begin{array}{l}\text { Without cortisol } \\
\text { variability }\end{array}$ & 12 & 10 & 8 & 8 & 7 & 5 & 5 & \\
\hline
\end{tabular}

Figure I Kaplan-Meier estimates for overall survival in the patients whose salivary cortisol levels decreased $>0.6 \mathrm{pg} / \mathrm{mL}$ or increased in the experimental group. reported that anxiety disorder predicted 1-year mortality and technique failure in patients receiving peritoneal dialysis. In patients receiving $\mathrm{HD}$, those with moderate depression scores were associated with higher overall mortality. ${ }^{38} \mathrm{Kim}$ et $\mathrm{a}^{39}$ found that depressive symptoms positively correlated with the severity of the left ventricular mass index and left

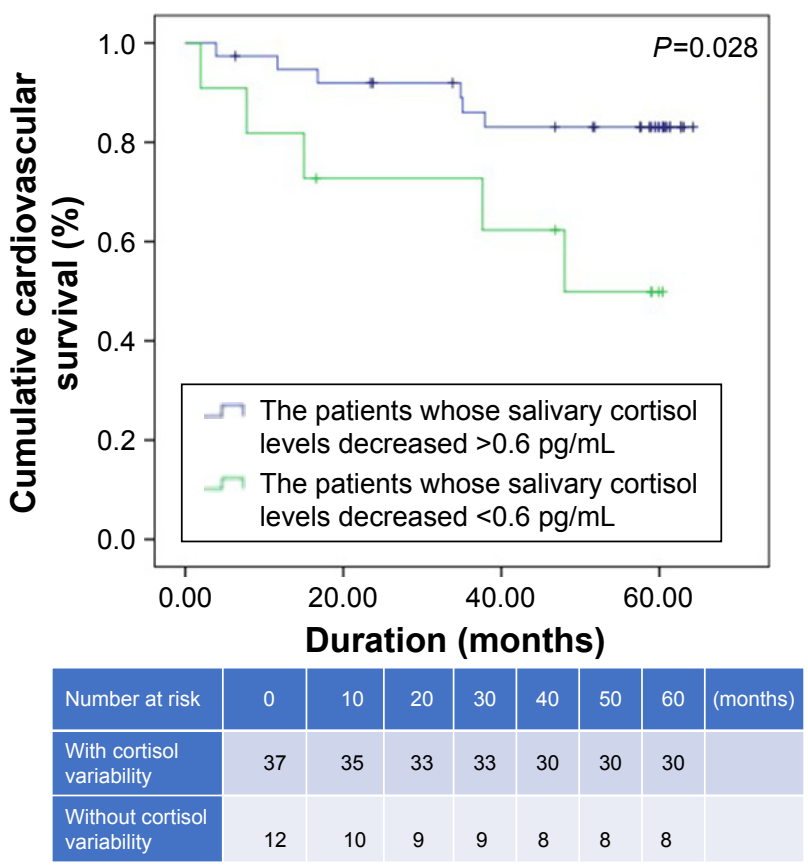

Figure 2 Kaplan-Meier estimates for cardiovascular survival in the patients whose salivary cortisol levels decreased $>0.6 \mathrm{pg} / \mathrm{mL}$ or increased in the experimental group. 
ventricular refilling pressure in HD patients. Although the mechanism of threat in the cardiovascular system by stress remains unclear, hypercortisolemia causes consequent insulin resistance and hyperglycemia is postulated..$^{40}$ Therefore, higher basal cortisol cause by mental stress could be hazardous to patients by disturbing the cardiovascular system. In our study, music therapy provides a predictive role for better regulation on cortisol release and the lowering cortisol predicts cardiovascular mortality in HD patients.

There are several limitations in our study. 1) We measured only predialysis cortisol level. We did not measure the salivary cortisol level during or after HD. 2) The experimental group received only 1 week of music therapy; therefore, the influence on other clinical outcomes could not be evaluated. 3) The number of patients in our study may not have been sufficient. Therefore, further study is necessary to understand more clearly the mechanism governing the cortisol-lowering effect of music in patients on maintenance HD.

\section{Conclusion}

Providing music during HD improves overall patient wellbeing by alleviating the frequency and severity of adverse reactions, as well as serum cortisol secretion. The decrease in cortisol correlates positively with HSS score and respiratory rates and negatively with oxygen saturation.

\section{Acknowledgments}

The study was supported by grants from Cardinal Tien Hospital and was approved by the Ethics Committee of Cardinal Tien Hospital, New Taipei City, Taiwan (registry number CTH-98-3-5-006). The protocol can be accessed at Cardinal Tien Hospital with protocol registry number CTH99-1-2A02. Y-JL is the principal investigator of the study. L-KY is the chief of the Hemodialysis Center of Cardinal Tien Hospital and the main physician of the participants.

\section{Author contributions}

Y-CH drafted the article and performed the statistics. Y-JL drafted the article equally to $\mathrm{Y}-\mathrm{CH}$ and collected data from the participants. K-CL and C-CC designed the protocol of the study. H-SC designed the music therapy (including the type, frequency, and duration of the music). All authors contributed toward data analysis, drafting and critically revising the paper and agree to be accountable for all aspects of the work.

\section{Disclosure}

The authors report no conflicts of interest in this work.

\section{References}

1. International Comparisons [webpage on the Internet]. Chap. 12: Atlas of end-stage renal disease in the United States. USRDS 2010 Annual Data Report. Vol 2. United States Renal Data System; 2013. Available from: https://www.usrds.org/adr.aspx. Accessed January 24, 2017.

2. Tan ZG, Yang WC. Artificial Kidney. Taipei: LeaderBook; 2005.

3. Perales-Montilla CM, García-León A, Reyes-del Paso GA. Psychosocial predictors of the quality of life of chronic renal failure patients undergoing haemodialysis. Nefrologia. 2012;32(5):622-630.

4. Zoccali C, Tripepi G, Mallamaci F. Predictors of cardiovascular death in ESRD. Semin Nephrol. 2005;25(6):358-362.

5. Di Lullo L, Rivera R, Barbera V, et al. Sudden cardiac death and chronic kidney disease: from pathophysiology to treatment strategies. Int J Cardiol. 2016;217:16-27.

6. Seliger SL, Katzel LI, Fink JC, Weir MR, Waldstein SR. Renal function and cardiovascular response to mental stress. Am J Nephrol. 2008; 28(2):304-310.

7. Myers B. Corticolimbic regulation of cardiovascular responses to stress. Physiol Behav. Epub 2016 Oct 25.

8. Hellhammer DH, Wust S, Kudielka BM. Salivary cortisol as a biomarker in stress research. Psychoneuroendocrinology. 2009;34(2):163-171.

9. Levine A, Zagoory-Sharon O, Feldman R, Lewis JG, Weller A. Measuring cortisol in human psychobiological studies. Physiol Behav. 2007; 90(1):43-53.

10. Vining RF, McGinley RA, Maksvytis JJ, Ho KY. Salivary cortisol: a better measure of adrenal cortical function than serum cortisol. Ann Clin Biochem. 1983;20(6):329-335.

11. Brown NJ, Kimble RM, Rodger S, et al. Biological markers of stress in pediatric acute burn injury. Burns. 2014;40(5):887-895.

12. González-Cabrera J, Fernández-Prada M, Iribar-Ibabe C, Peinado JM. Acute and chronic stress increase salivary cortisol: a study in the reallife setting of a national examination undertaken by medical graduates. Stress. 2014;17(2):149-156.

13. Wong JA, Pickworth WB, Waters AJ, al'Absi M, Leventhal AM. Cortisol levels decrease after acute tobacco abstinence in regular smokers. Hum Psychopharmacol. 2014;29(2):152-162.

14. Pahuja R, Kotchen TA. Salivary cortisol predicts cardiovascular mortality. Curr Hypertens Rep. 2011;13(6):404-405.

15. Kumari M, Shipley M, Stafford M, Kivimaki M. Association of diurnal patterns in salivary cortisol with all-cause and cardiovascular mortality: findings from the Whitehall II study. J Clin Endocrinol Metab. 2011; 96(5):1478-1485.

16. O'Sullivan RJ. A musical road to recovery: music in intensive care. Intensive Care Nurs. 1991;7(3):160-163.

17. Cook JD. Music as an intervention in the oncology setting. Cancer Nurs. 1986;9:23-28.

18. Koelsch S, Kasper E, Sammler D, Schulze K, Gunter T, Friederici AD. Music, language and meaning: brain signatures of semantic processing. Nat Neurosci. 2004;7(3):302-307.

19. Lee OK, Chung YF, Chan MF, Chan WM. Music and its effect on the physiological responses and anxiety levels of patients receiving mechanical ventilation: a pilot study. J Clin Nurs. 2005;14(5):609-620.

20. Updike P. Music therapy results for ICU patients. Dimens Crit Care Nurs. 1990;9(1):39-45.

21. Ventura T, Gomes M, Carreira T. Cortisol and anxiety response to a relaxing intervention on pregnant women awaiting amniocentesis. Psychoneuroendocrinology. 2012;37(1):148-156.

22. Trappe HJ. Role of music in intensive care medicine. Int J Crit Illn Inj Sci. 2012;2(1):27-31.

23. Thoma MV, La Marca R, Bronnimann R, Finkel L, Ehlert U, Nater UM. The effect of music on the human stress response. PLoS One. 2013;8(8):e70156.

24. Lin YJ, Lu KC, Chen CM, Chang CC. The effects of music as therapy on the overall well-being of elderly patients on maintenance hemodialysis. Biol Res Nurs. 2012;14(3):277-285. 
25. Taiwan Nephrology Nurses Association. Hemodynamic changes and their management during hemodialysis. Taiwan Nephrology Nurses Association, Discussion of clinical care in HD patients (2)-The management of blood pressure during hemodialysis [press release]. Taipei City, Taiwan. Symposium conducted at the meeting of the Taiwan Nephrology Nurses Association; 2007 [May].

26. Chou HC. Study for Stressors and Coping Methods among Chronic Hemodialysis Patients. Kaohsiung, Taiwan: National Sun Yat-sen University; 2002.

27. Raff H, Trivedi H. Circadian rhythm of salivary cortisol, plasma cortisol, and plasma ACTH in end-stage renal disease. Endocr Connect. 2012;2(1):23-31.

28. Luger A, Lang I, Kovarik J, Stummvoll HK, Templ H. Abnormalities in the hypothalamic-pituitary-adrenocortical axis in patients with chronic renal failure. Am J Kidney Dis. 1987;9(1):51-54.

29. Clodi M, Riedl M, Schmaldienst S, et al. Adrenal function in patients with chronic renal failure. Am J Kidney Dis. 1998;32(1):52-55.

30. Siamopoulos KC, Dardamanis M, Kyriaki D, Pappas M, Sferopoulos G, Alevisou V. Pituitary adrenal responsiveness to corticotropin-releasing hormone in chronic uremic patients. Peritoneal Dialysis International. 1990;10(2):153-156.

31. Wallace EZ, Rosman P, Toshav N, Sacerdote A, Balthazar A. Pituitaryadrenocortical function in chronic renal failure: studies of episodic secretion of cortisol and dexamethasone suppressibility. Journal of Clinical Endocrinology and Metabolism. 1980;50(1):46-51.

32. Grootendorst DC, de Jager DJ, Brandenburg VM, et al. Excellent agreement between $\mathrm{C}$-reactive protein measurement methods in end-stage renal disease patients - no additional power for mortality prediction with high-sensitivity CRP. Nephrol Dial Transplant. 2007;22(11): 3277-3284.
33. Spinedi E, Hadid R, Daneva T, Gaillard RC. Cytokines stimulate the $\mathrm{CRH}$ but not the vasopressin neuronal system: evidence for a median eminence site of interleukin-6 action. Neuroendocrinology. 1992; 56(1):46-53.

34. Nilsson U. Soothing music can increase oxytocin levels during bed rest after open-heart surgery: a randomised control trial. J Clin Nurs. 2009; 18(15):2153-2161.

35. Lesperance F, Frasure-Smith N, Talajic M, Bourassa MG. Five-year risk of cardiac mortality in relation to initial severity and one-year changes in depression symptoms after myocardial infarction. Circulation. 2002;105(9):1049-1053.

36. Kop WJ, Stein PK, Tracy RP, Barzilay JI, Schulz R, Gottdiener JS. Autonomic nervous system dysfunction and inflammation contribute to the increased cardiovascular mortality risk associated with depression. Psychosom Med. 2010;72(7):626-635.

37. Griva K, Kang AW, Yu ZL, et al. Predicting technique and patient survival over 12 months in peritoneal dialysis: the role of anxiety and depression. Int Urol Nephrol. 2016;48(5):791-796.

38. Saglimbene V, Palmer S, Scardapane M, et al. Depression and all-cause and cardiovascular mortality in patients on haemodialysis: a multinational cohort study. Nephrol Dial Transplant. Epub 2016 Mar 22.

39. Kim YK, Park CS, Ihm SH, et al. Relationship between the course of depression symptoms and the left ventricular mass index and left ventricular filling pressure in chronic haemodialysis patients. Nephrology (Carlton). 2011;16(2):180-186.

40. Weber-Hamann B, Kopf D, Lederbogen F, et al. Activity of the hypothalamus-pituitary-adrenal system and oral glucose tolerance in depressed patients. Neuroendocrinology. 2005;81(3):200-204. 


\section{Supplementary material}

Table SI The ranking of the experimental group according to the difference in salivary cortisol after listening to relaxing music therapy

\begin{tabular}{ll}
\hline Rank & Difference in salivary cortisol (pg/mL) \\
\hline 1 & -17.87 \\
2 & -8.1 \\
3 & -6.32 \\
4 & -6.09 \\
5 & -6.03 \\
6 & -5.6 \\
7 & -5.29 \\
8 & -5.25 \\
9 & -4.11 \\
10 & -3.99 \\
11 & -3.86 \\
12 & -3.67 \\
13 & -3.3 \\
14 & -3.18 \\
15 & -2.81 \\
16 & -2.77 \\
17 & -2.56 \\
18 & -2.38 \\
19 & -2.35 \\
20 & -2.19 \\
21 & -1.89 \\
\hline &
\end{tabular}

Table SI (Continued)

\begin{tabular}{ll}
\hline Rank & Difference in salivary cortisol $(\mathrm{pg} / \mathrm{mL})$ \\
\hline 22 & -1.88 \\
23 & -1.79 \\
24 & -1.76 \\
25 & -1.5 \\
26 & -1.43 \\
27 & -1.4 \\
28 & -1.39 \\
29 & -1.09 \\
30 & -1.05 \\
31 & -0.99 \\
32 & -0.91 \\
33 & -0.87 \\
34 & -0.86 \\
35 & -0.75 \\
36 & -0.75 \\
37 & -0.6 \\
38 & -0.48 \\
39 & -0.43 \\
40 & -0.42 \\
41 & -0.39 \\
42 & -0.39 \\
43 & -0.34 \\
44 & -0.29 \\
45 & 0.13 \\
46 & 0.31 \\
47 & 0.43 \\
48 & 0.59 \\
49 & 1.77 \\
\hline &
\end{tabular}

\section{Publish your work in this journal}

Therapeutics and Clinical Risk Management is an international, peerreviewed journal of clinical therapeutics and risk management, focusing on concise rapid reporting of clinical studies in all therapeutic areas, outcomes, safety, and programs for the effective, safe, and sustained use of medicines. This journal is indexed on PubMed Central, CAS,
EMBase, Scopus and the Elsevier Bibliographic databases. The manuscript management system is completely online and includes a very quick and fair peer-review system, which is all easy to use. Visit http://www.dovepress.com/testimonials.php to read real quotes from published authors. 